BMJ

Open

Gastroenterology

\title{
Role for structured telephone clinics in paediatric gastroenterology: reflections, lessons and patient feedback
}

\author{
Hazel Duncan, ${ }^{1}$ Richard K Russell ${ }^{2}$
}

To cite: Duncan H, Russell RK. Role for structured telephone clinics in paediatric gastroenterology: reflections, lessons and patient feedback. BMJ Open Gastro 2019;6:e000245. doi:10.1136/ bmjgast-2018-000245

- Additional material is published online only. To view please visit the journal online (http://dx.doi.org/10.1136/ bmjgast-2018-000245).

Received 3 September 2018 Revised 24 October 2018 Accepted 30 October 2018
Check for updates

\section{(c) Author(s) (or their} employer(s)) 2019. Re-use permitted under CC BY-NC. No commercial re-use. See rights and permissions. Published by BMJ.

${ }^{1}$ Department of Nutrition and Dietetics, The Royal Hospital for Children, Glasgow, UK

${ }^{2}$ Paediatric Gastroenterology Department, The Royal Hospital for Children, Glasgow, UK

Correspondence to Hazel Duncan;

hazel.duncan6@nhs.net

\section{ABSTRACT}

Background Telephone clinics have been established within our department to try and improve communication with families, limit waiting times and help face-to-face clinics run more efficiently. As part of the ongoing care needs for our patients and families it was felt important to determine if telephone clinics were meeting the needs of the young person and family as well as those of the health professional.

Objective To assess the effects of a structured consultant delivered telephone clinic.

Method Data were collected regarding patients who had a consultant telephone appointment between July 2016 and March 2017. Data collected include demographics and appointment reason. An evaluation questionnaire was sent to all parent/carer(s).

Results 25 clinics comprising 194 contacts, including 34 duplicate contacts. 120 questionnaires sent. 7/160 $(4.3 \%)$ were new patients. The main contact reason was biopsy results after endoscopy (93/180; 52\%). Failure to attend rate was significantly lower at $18 / 194(9.2 \%)$ compared with failure to attend rate of $52 / 240(21.6 \%)$ for a traditional clinic $(p<0.001) .40 / 120(33 \%)$ returned completed questionnaires, $25 / 40$ (68.4\%) reported the reason for appointment was test results. Travel time and school attendance were identified as main advantages. Mean parental rating score for the service was $8 / 10$ with $21 / 40$ (54\%) scoring the service as 10/10.

Conclusion The initial results of this audit are promising. Structured telephone appointments have a key role in delivering patient care in paediatric gastroenterology and have benefits to health professional, parent/carer and patients. These clinics have now been widely adopted by all members of our department.

\section{INTRODUCTION}

Telephone clinic reviews can be a useful tool to ensure patients receive timely care via a method that is time efficient to the provider and acceptable to patients and families. Telephone clinics have been well established in adult services for a number of years. A study by Hennell et al in 2005 reported on their experience of a nurse-led adult rheumatology clinic and highlighted that phone clinics had been an established part of care, for chronic
Summary box

What is already known about this subject?

- Telephone clinics are established within adult services and have been found to be useful in patients with chronic conditions.

- There is limited evidence regarding the use of these clinics in paediatrics and whether patients/service users find it helpful.

What are the new findings?

- The introduction of telephone clinics was well received with good feedback from parents/carers.

- The main use of the telephone clinic was to feedback test results within an appropriate timescale but can also be used for other patient contact purposes.

How might it impact on clinical practice in the foreseeable future?

The need for follow up with a traditional out patient appointment could instead be offered phone clinic follow up in some circumstances.

- Fixed timings means workload can be allocated accordingly and families can expect a dedicated rather than ad hoc time for feedback.

illness specifically, for a number of years ${ }^{1}$; however, evidence of telephone clinics in paediatric setting is lacking. As the demands on health services increase it is important that new ways of working are considered to improve waiting lists while ensuring the same quality of care to patients is delivered. Patients with chronic illness often need fast access to specialist health professionals to discuss issues. ${ }^{2}$ Telephone clinics have the added benefit of allowing healthcare professional to be able to streamline care.

Within the published literature there is clear evidence demonstrating the many benefits of telephone consultation service including telephone appointments being more convenient, more cost-effective, improved quality of care and decreased non-attendance rates. ${ }^{2-6}$ 
The gastroenterology service within our hospital encompasses a range of chronic conditions including inflammatory bowel disease (IBD), liver, complex nutrition and home parenteral nutrition. All patients require regular review, however it was felt this did not always have to be face-to-face. Alongside this there are a number of patients who will attend for procedures such as blood tests or endoscopy and need results delivered in a timely and organised manner.

The aim of this work is to assess the impact of consultant telephone service in a gastrointestinal (GI) service in a tertiary care centre and to carry out a service evaluation to assess the role of the telephone clinic service is meeting patients' needs.

\section{METHODS}

Previous practice prior to the use of phone clinics would be for patients who require results or review between face-to-face appointments would be for a clinician to call them ad hoc at a time that suited their diary, as the families were unaware of when these calls would happen they were often unavailable. The alternative to this (less often chosen) was to arrange a face-to-face review in clinic which was often not necessary but chosen as an option if a phone discussion could not take place. Endoscopy results would in the absence of phone or face-to-face review being possible be summarised in writing, however this did not facilitate a shared discussion of results taking place and organisation of a mutually agreed plan.

Due to increasing demands on face-to-face consultations the concept of telephone clinics within our service was explored. These were initially used for endoscopy results and then expanded to discuss other more complex results that could not be summarised by letter and for patients with sudden change in symptoms to allow quicker review than the outpatient department clinic. All patients who had undergone endoscopy were offered a telephone appointment to convey results with the date and time of the call given to the patient on the day of endoscopy.

The telephone clinics can be used for the benefit of patients knowing a time for a call without travel to the tertiary centre and to the benefit of health professional who can plan and use time more efficiently. Following the clinic the consultant dictates a letter to all patient/ carer(s) and when appropriate patients were sent a letter summarising the call, letters were also sent to general practitioner (GP) and other appropriate health professionals regarding the consultation.

The study was carried out in a tertiary paediatric centre. Patients were identified by their attendance at a consultant telephone clinic (RKR). These clinics were carried out on a weekly basis on an allocated day with eight scheduled appointments over 2 hours to allow time for the call, documentation, letter generation and follow-up plans to be put in place. Data were pulled from the hospital appointments management system from those who were appointed to telephone clinics between July 2016 and March 2017. Data collected from the appointment management system included type of appointment, purpose of appointment, planned follow-up and outcome documented.

Additionally a questionnaire was compiled using SurveyMonkey and sent out to all patients/carers who were identified as having been involved in a telephone appointment. The questionnaire was sent with a stamped address envelope and return date within 2 weeks of posting. A follow-up reminder was sent prior to the deadline. The full questionnaire is included (online supplementary appendix 1). A further questionnaire was sent to departmental staff who were affected by telephone clinics for feedback regarding the introduction of the service.

Categorical variables were compared using $\chi^{2}$ test or Fischer's exact test as appropriate. Statistical significance was defined as $p$ value below 0.05 . As a service evaluation project we have clarified from our ethics committee previously that no formal ethical approval was needed for this type of study.

\section{RESULTS}

There were 194 patients appointed to telephone clinic between July 2016 and March 2017. Of these, 18/194 $(9.2 \%)$ failed to be contacted and were classified as a did not attend (DNA), 34/176 (19.3\%) were duplicate appointments with the highest number of repeat appointments being 6 . Full data were available for 160 patients; 120 participants were eligible to receive a questionnaire.

\section{Demographics}

Of the patients allocated a telephone review 80/160 $(50 \%)$ were male; median age 13 years (IQR: 7.3115.66 years). Diagnoses are listed in table 1 with the most common being IBD $(50 / 160 ; 31.25 \%)$. From the data collected from the electronic appointment system $7 / 160(4.3 \%)$ were new patients with no previous faceto-face consultation at the tertiary hospital. Reasons for the new patient appointments included referral from district general hospital $(4 / 7 ; 57 \%), 2 / 7$ (28.5\%) pre-endoscopy and $1 / 7(14.2 \%)$ symptom review prior to face-to-face consultation. All reasons for telephone appointment are shown in figure 1 . The most common reason for a telephone appointment was to convey biopsy results from an endoscopy and make ongoing plans based on these $(93 / 180 ; 52 \%)$. The median time from endoscopy to results via telephone was 16 days (IQR: 14-20 days).

The DNA rate for telephone consultation was 18/194 $(9.2 \%)$. Data were pulled using the electronic appointment system to compare DNA rates with a face-to-face gastroenterology with the consultant clinic over the same timescale. The face-to-face clinic had a significantly higher DNA rate of 52/240 (21.6\%) $(\mathrm{p}<0.001)$. 
Table 1 Diagnosis of paediatric patients within telephone clinic $(n=160)$

\begin{tabular}{ll}
\hline Diagnosis & Number of patients (n=160) \\
\hline IBD & 50 \\
\hline Abdominal pain & 32 \\
\hline Gastro-oesophageal reflux & 17 \\
\hline Loose stools & 13 \\
\hline Eosinophilic oesophagitis & 9 \\
\hline Coeliac disease & 6 \\
\hline Epigastric pain & 6 \\
\hline Cow's milk protein allergy & 4 \\
\hline Rectal bleeding & 4 \\
\hline Vomiting & 4 \\
\hline Constipation & 2 \\
\hline Disaccharide deficiency & 2 \\
\hline Eating disorder & 2 \\
\hline Other (bleeding, allergy) & 2 \\
\hline Faltering growth & 1 \\
\hline Gl dysmotility & 1 \\
\hline Juvenile arthritis & 1 \\
\hline Polyposis & 1 \\
\hline Proctitis & 1 \\
\hline Recurrent haematemesis & 1 \\
\hline Unsettled & 1 \\
\hline & \\
\hline
\end{tabular}

GI, gastrointestinal; IBD, inflammatory bowel disease

\section{Questionnaire}

Questionnaires were sent to 120 parents/carers. Following a reminder questionnaire the response rate was $40 / 120(33 \%)$.

The majority of patients $(16 / 40 ; 39.8 \%)$ reported having had one telephone appointment; $3 / 40$ (7.5\%) reported receiving more than five telephone appointments during the study period. Informing families of test results was the most common reason for appointment $(27 / 40 ; 67.5 \%), 4 / 40(10 \%)$ was an update regarding care

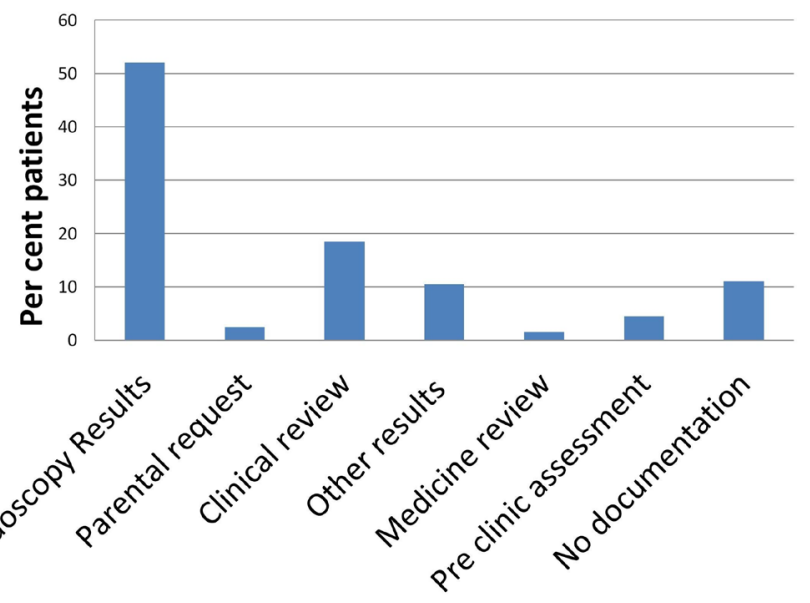

Figure 1 Reasons for telephone appointment.

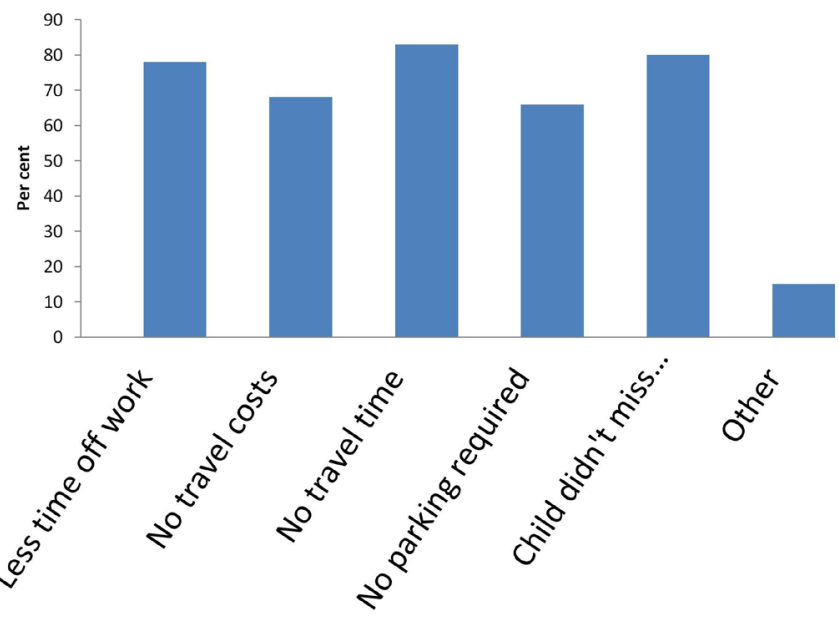

Figure 2 Parent/carers' advantages of telephone appointment.

and $7 / 40(17.5 \%)$ reports the purpose of the contact was a new problem or concern. Only $1 / 40(2.5 \%)$ reported the purpose of the contact was for a second opinion and $5 / 40(12.5 \%)$ of parents/carers reported they had not had a face-to-face consultation prior to the telephone consultation.

The main advantage of telephone consultation (see figure 2) was reported to be no travel time $(34 / 40 ; 85 \%)$, closely followed by the child not requiring time off school $(33 / 40 ; 82.5 \%)$. The main disadvantage was prefer faceto-face consultation $(5 / 40 ; 12.5 \%)$ and lack of physical examination $(4 / 40 ; 10 \%)$. Other disadvantages include discussion not thorough enough $(1 / 40 ; 2.5 \%)$, did not feel listened too $(1 / 40 ; 2.5 \%)$, poor reception $(1 / 40$; $2.5 \%)$ and felt unable to ask questions $(1 / 40 ; 2.5 \%)$.

All parents/carers reported the health professional introduced themselves and 39/40 (97.5\%) felt listened to. One hundred per cent reported the consultation met the needs of their child. Thirty-eight of $39(97.4 \%)$ reported follow-up plans for their child were clear. There was a significant preference for avoiding face-to-face consultation, $24 / 40(60 \%)$ vs $6 / 40(15 \%)$ who preferred face-to-face $(\mathrm{p}<0.0001)$, with $10 / 40(25 \%)$ undecided. One hundred per cent parents/carers reported they were happy with the interaction at clinic. When scoring the service $21 / 40(52.5 \%)$ scored the service as $10 / 10$. Mean score was 8/10.

Any further comments regarding the telephone service given as free text are shown in table 2 .

\section{Service user's feedback}

Questionnaires were also sent to our staff involved in telephone clinics including clerical staff, other consultants and pathologists. Response rate was $75 \%$. Of those who returned $2 / 3(66 \%)$ were secretary with one typist. They all felt telephone clinics had improved the service for patients, $2 / 3(66 \%)$ felt it was easier for patients contacting department looking to speak with a member of staff to be dealt with as they are often able to allocate straight into an appointment slot to secure a return call. 
Table 2 Parental/carers' comments regarding telephone service

A combination of

telephone and face-to-face appointments was felt to be important.

Useful to have prearranged call time

The appointment was helpful and informing.

Excellent service

The doctor has provided exceptional patient centre

Very beneficial care to our son.

$\begin{array}{ll}\text { Very grateful } & \text { Impressec } \\ \text { service }\end{array}$

The clerical team reported that they felt their workload had increased following the introduction of telephone clinics. Advantages and disadvantages identified by the clerical team are visible in table 3 . Overall, despite the increase in workload, they felt the telephone service was advantageous for patients/parents and carers.

Other consultants felt that telephone clinics had improved the service for patients but that there was an increased workload on secretarial staff for typing letters. Both consultants felt telephone clinics had allowed more effective time management and allowed protected time to make calls. Disadvantages were identified as being increased work for secretaries and one consultant felt that they often had repetitive conversations with families.

The pathology department reported that provided they had knowledge of planned review date when biopsies were submitted then the service was beneficial to staff and patients. They went onto report that on rare occasions staffing pressures meant they were unable to report in the timescale, however they could only recall this happening on a few occasions over the time period studied.

\section{DISCUSSION}

Telephone clinics, as part of chronic disease management, can be extremely beneficial to both patients, families and health professionals. This audit has demonstrated a high level of satisfaction for those patients who received a telephone consultation and then returned a questionnaire in

\begin{tabular}{ll}
\hline \multicolumn{2}{l}{$\begin{array}{l}\text { Table } 3 \\
\text { reported by clerical team }\end{array}$} \\
\hline Advantages & Disadvantages \\
\hline No long wait face-to-face & No clinical examination \\
& $\begin{array}{l}\text { Phone reception can be } \\
\text { variable }\end{array}$ \\
Point of contact & Extra letters generated \\
No travel issues & Extra appointment times \\
Easier for clinical review & More typing required \\
\hline Issues dealt with quicker & \\
\hline
\end{tabular}

the setting of a paediatric gastroenterology service. This has allowed prioritisation of face-to-face clinic appointments. Evidence supporting telephone clinics within the paediatric GI cohort is limited and to our knowledge this is the first patient satisfaction review of this type of general GI clinic which is not disease specific.

A service evaluation on the introduction of telephone service in adult urology patients found $91.9 \%$ participants reported telephone consultation was more convenient due to no travel time or time to be seen. ${ }^{3}$ This finding was replicated by Hennell et al ${ }^{1}$ who reviewed patient satisfaction of nurse-led adult rheumatology telephone clinic. ${ }^{1}$ They reported $72 \%$ of patients felt happy with telephone service provided and would be willing to use the service again. Although based on adults both these studies have similar results to ourselves following our service review in Glasgow which found that all parents/carers felt the telephone appointment met their child's needs and scored the overall service very highly $(52.5 \%$ scored service as $10 / 10)$.

Many of the telephone studies carried out are within the adult population, ${ }^{2578}$ despite this a similar message can be extrapolated to the paediatric population. A systematic review and meta-analysis of randomised controlled trials (RCT) looking at distance management and standard follow-up in management of adult patients with IBD defined distance management as being a method to manage patients remotely including telemedicine, web-based intervention and telephone clinics. ${ }^{7}$ Following review of six adult RCTs of which all patients had IBD they reported that while distance management decreased clinical utilisation it does not directly improve patient's quality of life (QoL), relapse rates or hospital admission rates. Additionally they state that further studies are needed to determine the best type of approach for this patient group and further RCTs are needed to ensure distance management is optimal and effective.

A review of introduction of a nurse-led telephone clinic for patients with $\mathrm{IBD}^{8}$ demonstrated from a retrospective review that the introduction of a telephone service significantly reduced the non-attendance rate and waiting times for urgent appointments. Patients were either offered a face-to-face or telephone review prior to their conventional clinic appointment; 49/158 opted for a telephone review appointment. 95\% of respondents were satisfied with the service they received within the telephone clinic. Over the study period the DNA rate for telephone clinics reduced by over $50 \%$ compared with face-to-face consultation. Waiting times for conventional face-to-face clinic appointments reduced from 12 weeks to 8 weeks. While the data are promising with $95 \%$ patients reporting they were satisfied with the service the results cannot be fully compared with our own as they selected appropriate patients for telephone review and only within an IBD cohort. A similar review also demonstrated that telephone support to patients with IBD reduced unnecessary follow-up, provided rapid review during periods of relapse and promoted individualised patient care in 
adult patients with IBD. ${ }^{2}$ While these two studies are in adult patients with IBD they highlight results similar to our own audit which demonstrated that non-attendance rates for our telephone audit were $9.2 \%$ compared with a non-attendance rate of $21.6 \%$ for face-to-face clinic.

The core remit for our initial institution of the telephone service was provision of results and clinical review following a medication change or parental request. However, over time it became clear that the clinic could be additionally used for assessment of some types of new patients. Patients referred from the district general hospitals often have had all preliminary tests and are aware that they require further testing, a face-to-face review appointment may not add anything further and therefore a telephone review appointment can discuss planned procedures with a shorter wait compared with traditional appointment. This meant seven new patients who had not previously had a face-to-face appointment and would have had to wait longer to receive a face-toface appointment and thereby longer to secure a diagnosis. This is a novel aspect to our study as there were no other centres found who were offering telephone consultation appointments to new appropriate patients.

Akobeng et al carried out an RCT in 2015 within paediatric IBD group. ${ }^{4}$ They compared effectiveness and cost consequences of telephone clinic against traditional consultation. The Manchester group recruited 86 patients between ages 8 and 16 years, 44 were randomised to telephone contact and 42 face-to-face contact; they collected data at baseline, 12 and 24 months. IMPACT Quality of Life (QOL) scoring at 12 months showed no significant difference between SOL scores within the two patient groups. With regard to their secondary outcomes they reported no statistical significance between the two groups with regard to weight, height or body mass index $\mathrm{z}$ scores. They reported a statistical significant lower mean consultation time for telephone consultations at $9.8 \mathrm{~min}$ compared with $14.3 \mathrm{~min}$ for traditional consultation $(p<0.001)$. There were no adverse events noted in either group. To the best of our knowledge this is the only RCT looking at paediatrics IBD telephone consultation and while our telephone service is aimed at all gastroenterology patients and not just IBD specific a large cohort will have IBD making the QoL scoring relevant to our patient group. While this study was single centred the initial results are positive that telephone consultations do not have a detrimental impact on QoL of this patient group.

\section{Limitations}

The questionnaire response rate was low at 33\% despite a reminder being sent. Possible reasons may include the questionnaire being sent via post with return envelope, people having moved address or parents/carers being unwilling to share their experiences of the service. The population size was also relatively small and single centred, however was fully representative of typical paediatric gastroenterologist case load within a tertiary centre, meaning that many of the key messages and our results regarding patient/carer satisfaction within the telephone service has meant that we have now rolled out the telephone clinic service to subspecialities within our team.

\section{CONCLUSION}

From the evidence presented it is clear that telephone clinics are effective with advantages to both patient, parent/carers and health professionals. Our study demonstrates that the introduction of a telephone service has been seen positively by the majority of families. The telephone appointment service is meeting the needs of both follow-up and selected new patients plus improving time efficiency for health professionals and parents/carers. Overall the telephone clinic appointment service has been seen as a positive development within our service and has now expanded to include use by other consultants, specialist nurses and dietitians. Within the context of Telehealth this initial approach using telephone calls could be expanded or enhanced to include video consultations, 'virtual clinics' with GPs or district general hospitals or real-time summaries where the results can be documented with the patient during the consultation.

Contributors HD prepared the manuscript with comments and corrections from all the authors. HD collected the patient data. HD and RKR carried out the statistical analysis. All authors have read and approved the final draft. RKR acts as the guarantor for the article.

Funding The IBD team at the Royal Hospital for Children, Glasgow are supported by the Catherine McEwan Foundation and Yorkhill IBD fund who have helped fund this study. RKR is supported by an NHS Research Scotland Senior fellowship award.

Competing interests RKR has received speaker fees and travel support, and participated in medical board meetings with AbbVie, Therakos, Celltrion, Nestle and Ferring Pharmaceuticals.

Patient consent for publication Not required.

Provenance and peer review Not commissioned; externally peer reviewed.

Open access This is an open access article distributed in accordance with the Creative Commons Attribution Non Commercial (CC BY-NC 4.0) license, which permits others to distribute, remix, adapt, build upon this work non-commercially, and license their derivative works on different terms, provided the original work is properly cited, appropriate credit is given, any changes made indicated, and the use is non-commercial. See: http://creativecommons.org/licenses/by-nc/4.0/

\section{REFERENCES}

1. Hennell S, Spark E, Wood B, et al. An evaluation of nurse-led rheumatology telephone clinics. Musculoskeletal Care 2005;3:233-40.

2. Miller L, Caton S, Lynch D. Telephone clinic improved quality of follow up care for chronic bowel disease. Nurs Times. 2002;2002:36-8. and.

3. Wylie K, Allen P, Hallam-Jones R. An evaluation of a telephone followup clinic in urology. J Sex Med. 2005;2:641-4. and.

4. Akobeng AK, O'Leary N, Vail A, et al. Telephone Consultation as a Substitute for Routine Out-patient Face-to-face Consultation for Children With Inflammatory Bowel Disease: Randomised Controlled Trial and Economic Evaluation. EBioMedicine 2015;2:1251-6.

5. Pinnock H, Adlem L, Gaskin S, et al. Accessibility, clinical effectiveness, and practice costs of providing a telephone option for routine asthma reviews: phase IV controlled implementation study. $\mathrm{Br}$ $J$ Gen Pract 2007;57:714-22.

6. Car J, Sheikh A. Telephone consultations. BMJ 2003;326:966-9.

7. Huang VW, Reich KM, Fedorak RN. Distance management of inflammatory bowel disease: systematic review and meta-analysis. World J Gastroenterol 2014;20:829-42. 
8. Gethins S, Robinson R, de Caestecker J, et al. Impact of a nurseled telephone clinic on quality of IBD care. Gastrointestinal Nursing

2007;5:34-9. 